\title{
Long-term degradation of resin-based cements in substances present in the oral environment: influence of activation mode
}

\author{
Eduardo Moreira da SILVA', Jaime Dutra NORONHA-FILHO², Cristiane Mariote AMARAL³, Laiza Tatiana POSKUS ${ }^{3}$, \\ José Guilherme Antunes GUIMARÃES ${ }^{1}$
}

\begin{abstract}
1- DDS, MSc, PhD, Associate Professor, Analytical Laboratory of Restorative Biomaterials - LABiom-R, School of Dentistry, Federal Fluminense University, Niterói, RJ, Brazil.

2- MSc, PhD student, Analytical Laboratory of Restorative Biomaterials - LABiom-R, School of Dentistry, Federal Fluminense University, Niterói, RJ, Brazil. 3- DDS, MSc, PhD, Assistant Professor, Analytical Laboratory of Restorative Biomaterials - LABiom-R, School of Dentistry, Federal Fluminense University, Niterói, RJ, Brazil.
\end{abstract}

Corresponding address: Eduardo Moreira da Silva - Faculdade de Odontologia, Universidade Federal Fluminense - Rua Mário Santos Braga, $\mathrm{n}^{\circ} 30$ - Campus Valonguinho, Centro - Niterói - RJ - Brasil - 24020-140 - Phone: 5521 2629-9832 - Fax: 5521 2622-5739 - e-mail: emsilva@vm.uff.br

Received: January 8, 2013 - Modification: March 27, 2013 - Accepted: May 6, 2013

\section{ABSTRACT}

Tndirect restorations in contact with free gingival margins or principally within the gingival 1 sulcus, where the presence of organic acids produced by oral biofilm is higher, may present faster degradation of the resin-based cement pellicle. Objectives: To investigate the degradation of four resin-based cements: Rely X ARC (R), Variolink II (V), Enforce (E) and All Cem (A), after immersion in distilled water (DW), lactic acid (LA) and artificial saliva (AS) and to analyze the influence of the activation mode on this response. Material and Methods: Two activation modes were evaluated: chemical (Ch) and dual (D). In the dual activation, a two-millimeter thick ceramic disk (IPS Empress System) was interposed between the specimen and light-curing unit tip. Specimens were desiccated, immersed in distilled water, artificial saliva and lactic acid $0.1 \mathrm{M}$ at $37^{\circ} \mathrm{C}$ for 180 days, weighed daily for the first 7 days, and after 14, 21, 28, 90 and 180 days and were desiccated again. Sorption and solubility $\left(\mu \mathrm{g} / \mathrm{mm}^{3}\right)$ were calculated based on ISO 4049 . The data were submitted to multifactor analysis of variance (MANOVA) and Tukey's HSD test for media comparisons $(a=0.05)$. Results: Sorption was higher after immersion in LA $(p<0.05)$ and increased significantly with time $(p<0.05)$. Sorption was influenced by the activation mode: $C h>D$ $(p<0.05)$. The lowest solubility was presented by $R(p<0.05)$. Conclusions: Lactic acid increased the degradation of resin-based cements. Moreover, the physical component of activation, i.e., light-activation, contributed to a low degradation of resin-based cements.

Key words: Resin cements. Sorption. Solubility. Degradation. Lactic acid.

\section{INTRODUCTION}

In state-of-the-art restorative dentistry, there has been a significant increase in the development and use of ceramic materials for esthetic restorations. The clinical longevity of this type of restoration is related to the operator skill, mechanical properties of the ceramic material and, principally, to the performance of the tooth-restoration adhesive interface $2,4,5$. For esthetic reasons, particularly in indirect restorations in anterior teeth, the cervical margins of ceramic restorations are often located close to the free gingival margin or even within the gingival sulcus ${ }^{3}$. Consequently, the resin-based luting cement film is located in an area where there is a high concentration of organic acids produced by oral biofilm (lactic acid, propionic acid, acetic acid and formic acid) $)^{6,9}$.

Resin-based cements are basically constituted from photo-initiator substances, pigments, small amounts of filler particles and mainly methacrylate monomers such as Bis-GMA, UDMA and TEGDMA. Their polymerization mechanism involves a free radical polymerization reaction, which leads to a viscoelastic transformation into a rigid stage ${ }^{28}$. 
It is well known that the greater the degree of conversion, i.e., the amount of $\mathrm{C}=\mathrm{C}$ bonds from dimethacrylate monomers broken during this polymerization reaction, the lower the solubility and the sorption suffered by the material.

The use of sorption and solubility parameters as a method to analyze the degradation of resin-based materials is well established in the literature ${ }^{16,22,30}$. Sorption is a diffusion-controlled process represented by the amount of fluid that penetrates materials when they are immersed in an aqueous media. This phenomenon is influenced by two main factors: dimethacrylate monomer polarity, defined by the concentration of polar sites capable of forming hydrogen bonds with water (-OH in the Bis-GMA, -O- in TEGDMA and - $\mathrm{NH}$ - in UDMA), and the polymer network structure formed after polymerization ${ }^{23}$. The amount of non-reacted dimethacrylate monomers that undergoes lixiviation in an aqueous media determines the material solubility. The degree of conversion strongly influences this process. In other words, a resinbased material with a low degree of conversion has more non-reacted monomers and is more prone to solubility ${ }^{10}$.

In recent years, published studies have shown that lactic, propionic and acetic acid increased the degradation of restorative resin composites and adhesive systems ${ }^{25,26}$. Thus, considering that resin-based cements are composed of methacrylate monomers, and so are restorative resin composites, it seems reasonable to imagine that the same phenomenon may occur with these cements. Therefore, the aim of this study was to investigate the degradation of four resin-based cements immersed in substances present in the oral environment and the influence of the activation mode on this response. The test hypotheses were: 1) immersion in lactic acid would increase the degradation (sorption and solubility) of resin-based cements; 2) dual activation would lead to a lower degradation than chemical activation.

\section{MATERIAL AND METHODS}

The composition of resin-based cements is presented in Figure 1. All the specimens in the dual activation mode group were light-activated with a quartz-tungsten-halogen unit (Optilux 501, Demetron Inc. Danbury, USA) using an irradiance of $650 \mathrm{~mW} / \mathrm{cm}^{2}$ for $40 \mathrm{~s}$.

\section{Sorption and solubility}

Disc-shaped specimens were built up by filling an aluminum mold ( $1 \mathrm{~mm}$ thick and $6 \mathrm{~mm}$ in diameter). For the specimens subjected to chemical activation, the mold was filled to excess, the specimen surface was then covered with a polyester strip and a black mask, and compressed with a device $(500 \mathrm{~g})$ for 20 $s$ to avoid porosities. After reaching a rigid stage (15 $\mathrm{min}$ ) the specimens were placed in light-proof containers. For the dual-activation, after the same procedure as for the chemical-activation (except for placement of a black mask), a ceramic disk $12 \mathrm{~mm}$ in diameter and $2.0 \mathrm{~mm}$ thick, consisting of a $1 \mathrm{~mm}$ thick framework made of a castable pressed ceramic, (whose surface was etched with $10 \%$ hydrofluoric acid for $20 \mathrm{~s}$, rinsed for $30 \mathrm{~s}$, and air dried) and a $1 \mathrm{~mm}$ thick layering ceramic (IPS-Empress 2 system, Ivoclar Vivadent, Schaan, Liechtenstein) was placed between the mixed resinbased cement and the light unit, and the specimens were light activated.

For each activation mode, the specimens were individually stored in plastic vials, placed in a desiccator containing freshly dried silica gel, and transferred to an oven at $37^{\circ} \mathrm{C}$. After $24 \mathrm{~h}$, the discs were repeatedly weighed on an analytical balance (AUW 220D/0.01 mg, Shimadzu, Tokyo, Japan) until a constant mass $\left(m_{1}\right)$ was attained, i.e., disc mass variation was less than $\pm 0.1 \mathrm{mg}$ in any $24 \mathrm{~h}$ period. The thickness and the diameter of the discs were measured at four points, using a digital caliper (MPI/E-101, Mitutoyo, Tokyo, Japan),

\begin{tabular}{|c|c|c|c|}
\hline Material & Manufacturer & Composition & Filler (wt\%) \\
\hline All Cem & $\begin{array}{c}\text { FGM Dental Products } \\
\text { (Joinville, SC, Brazil) }\end{array}$ & $\begin{array}{c}\text { Bis-GMA, Bis-EMA, TEGDMA, Ba-Al-silicate glass, } \\
\text { silane treated silica, benzoyl peroxide, co-initiators and } \\
\text { camphorquinone. }\end{array}$ & 68 \\
\hline Variolink II & $\begin{array}{c}\text { Ivoclar Vivadent, Schaan, } \\
\text { Liechenstein }\end{array}$ & $\begin{array}{c}\text { Bis-GMA, UDMA, TEGDMA, barium glass, ytterbium } \\
\text { trifluoride, Ba-Al-fluorosilicate glass, zirconia/silica, } \\
\text { benzoyl peroxide, initiators, stabilizers and pigments. }\end{array}$ & 71 \\
\hline Enforce & Dentsply & $\begin{array}{c}\text { BisGMA, TEGDMA, BHT, EDAB, fumed silica, silanized } \\
\text { barium, aluminum borosilicate glass. }\end{array}$ & 66 \\
\hline Rely-X ARC & 3M-ESPE, St. Paul, MN, \\
USA & $\begin{array}{c}\text { Bis-GMA, TEGDMA, zirconia/silica filler, pigments, benzoyl } \\
\text { peroxide, amine and photoinitiator. }\end{array}$ & 67.5 \\
\hline
\end{tabular}

Figure 1- Resin-based cements used in the study 
and the volume (V) was calculated in $\mathrm{mm}^{3}$. After this, for each activation mode, the specimens were assigned into three groups of five specimens each $(n=5)$ according to the media immersion: the plastic vials were filled with $10 \mathrm{ml}$ of distilled water, artificial saliva ( $\mathrm{KCl}, \mathrm{NaCl}, \mathrm{MgCl}, \mathrm{CaCl}$, Nipagin, $\mathrm{CNC}$, Sorbitol, and deionized water - neutral $\mathrm{pH}$ ) or lactic acid 0.1 $\mathrm{M}(\mathrm{pH}=4)$ at $37 \pm 1^{\circ} \mathrm{C}$. Subsequently, the specimens were weighed daily for the first seven days, and then after time intervals of $14,21,28,90$, and 180 days $\left(m_{2}\right)$. Before being weighed, the specimens were blotted dry with absorbent paper. After 180 days, the specimens were placed in a desiccator and weighed daily until the mass variation was less
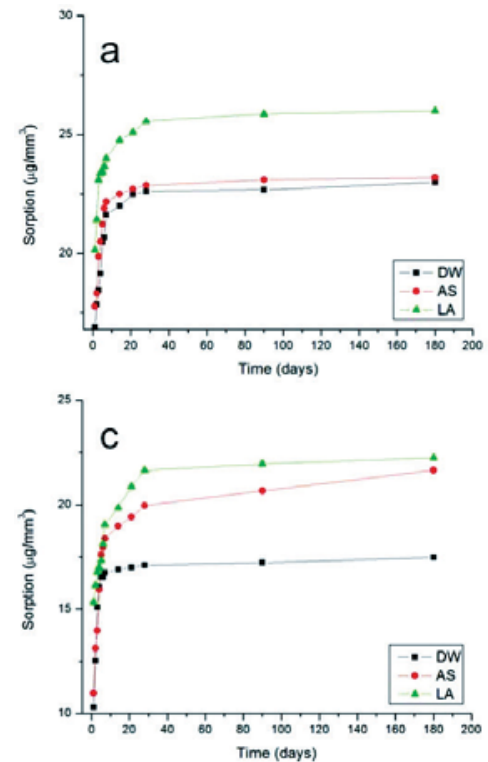

than $\pm 0.1 \mathrm{mg}\left(\mathrm{m}_{3}\right)$. The sorption ( $\mathrm{Sp}$ ) at each time interval and the solubility (SI) during the course of the 180 days of media immersion were obtained using the following formulae $\left(\mu \mathrm{g} / \mathrm{mm}^{3}\right)$ :

$$
\begin{aligned}
& S p=\frac{m_{2}-m_{3}}{V} \\
& S l=\frac{m_{1}-m_{3}}{V}
\end{aligned}
$$

\section{Statistical analysis}

Statistical analysis was performed using the Statgraphics 5.1 Software (Manugistics, Rockville, MD, USA). The sorption and solubility data were
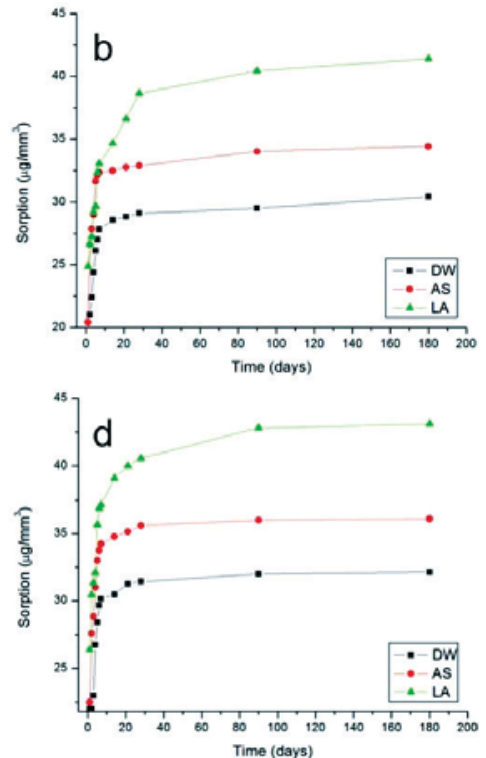

Figure 2- Increase in sorption as a function of time for dual-activation mode. In (a) All Cem; (b) Enforce; (c) Rely X ARC and (d) Variolink II
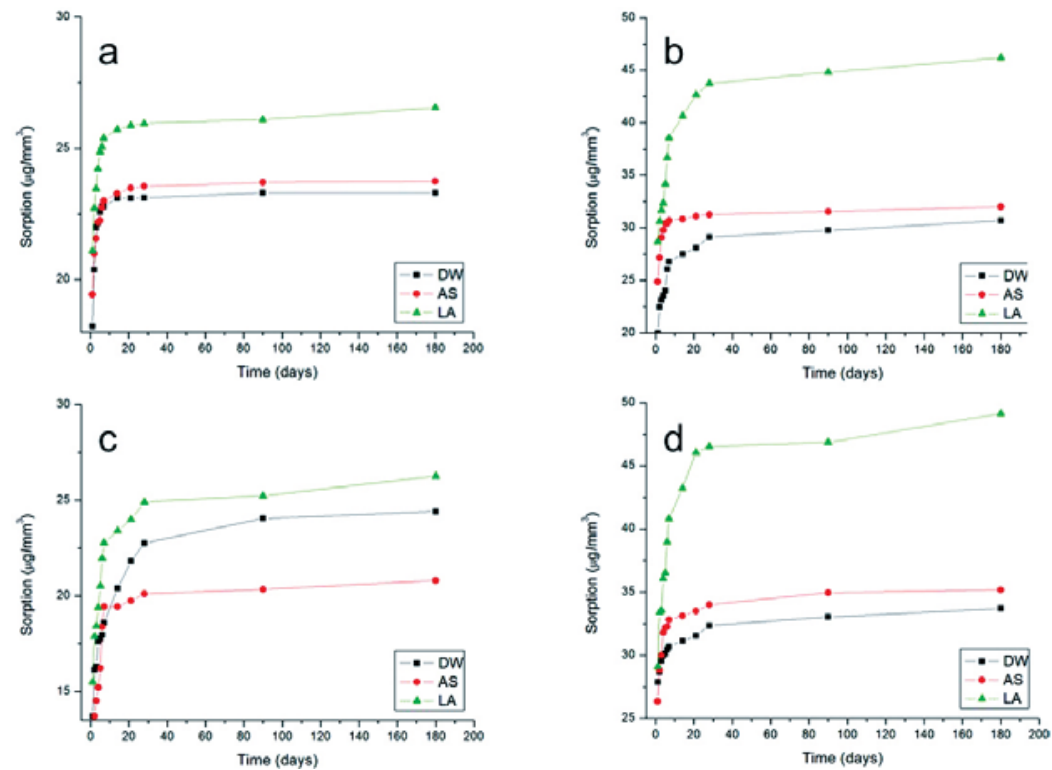

Figure 3- Increase in sorption as a function of time for chemical-activation mode: In (a) All Cem; (b) Enforce; (c) Rely X ARC and (d) Variolink II 
Table 1- Means \pm standard deviations of sorption $\left(\mu \mathrm{g} / \mathrm{mm}^{3}\right)$

\begin{tabular}{|c|c|c|c|c|c|c|}
\hline \multirow{2}{*}{$\begin{array}{c}\text { Resin-based } \\
\text { cement }\end{array}$} & \multicolumn{2}{|c|}{ Distilled water } & \multicolumn{2}{|c|}{ Artificial saliva } & \multicolumn{2}{|c|}{ Lactic acid } \\
\hline & Chemical & Dual & Chemical & Dual & Chemical & Dual \\
\hline All Cem & $23.3 \pm 0.4^{\mathrm{c}, \mathrm{b}}$ & $23.0 \pm 0.2^{\mathrm{B}, \mathrm{b}}$ & $23.7 \pm 0.6^{c, b}$ & $23.2 \pm 0.5^{\mathrm{B}, \mathrm{b}}$ & $26.6 \pm 0.3^{\mathrm{c}, \mathrm{a}}$ & $26.0 \pm 0.1^{\mathrm{B}, \mathrm{a}}$ \\
\hline Enforce & $30.7 \pm 0.8^{\mathrm{B}, \mathrm{d}}$ & $30.6 \pm 0.5^{A, d}$ & $32.0 \pm 1.3^{\mathrm{B}, \mathrm{C}}$ & $34.4 \pm 0.5^{\mathrm{A}, \mathrm{c}}$ & $46.2 \pm 0.7^{\mathrm{B}, \mathrm{a}}$ & $41.4 \pm 0.6^{\mathrm{A}, \mathrm{b}}$ \\
\hline Rely X & $24.4 \pm 1.4^{\mathrm{c}, \mathrm{a}, \mathrm{b}}$ & $17.5 \pm 1.3^{\mathrm{C}, \mathrm{d}}$ & $20.8 \pm 1.7^{\mathrm{D}, \mathrm{c}}$ & $21.7 \pm 1.7^{\mathrm{B}, \mathrm{c}}$ & $26.3 \pm 1.6^{\mathrm{C}, \mathrm{a}}$ & $22.3 \pm 1.8^{\mathrm{c}, \mathrm{b}, \mathrm{c}}$ \\
\hline Variolink II & $33.7 \pm 0.4^{A, c, d}$ & $32.1 \pm 1.5^{\mathrm{A}, \mathrm{d}}$ & $35.2 \pm 0.9^{A, C}$ & $36.1 \pm 1.3^{\mathrm{A}, \mathrm{C}}$ & $49.2 \pm 0.5^{\mathrm{A}, \mathrm{a}}$ & $43.1 \pm 0.8^{A, b}$ \\
\hline
\end{tabular}

In each column, values with identical capital letters are similar (Tukey HSD, p>0.05)

In each row, values with identical lower case letters are similar (Tukey HSD, $p>0.05$ )

Table 2- Means \pm standard deviations of solubility $\left(\mu \mathrm{g} / \mathrm{mm}^{3}\right)$

\begin{tabular}{|c|c|c|c|c|c|c|}
\hline \multirow[t]{2}{*}{ Resin-based } & \multicolumn{2}{|c|}{ Distilled water } & \multicolumn{2}{|c|}{ Artificial saliva } & \multicolumn{2}{|c|}{ Lactic acid } \\
\hline & Chemical & Dual & Chemical & Dual & Chemical & Dual \\
\hline All Cem & $5.4 \pm 0.1^{\mathrm{A}, \mathrm{a}}$ & $5.4 \pm 0.1^{\mathrm{A}, \mathrm{B}, \mathrm{a}}$ & $5.8 \pm 0.1^{\mathrm{A}, \mathrm{a}}$ & $5.5 \pm 0.1^{\mathrm{A}, \mathrm{a}}$ & $5.9 \pm 0.1^{\mathrm{A}, \mathrm{a}}$ & $5.8 \pm 0.1^{\mathrm{A}, \mathrm{a}}$ \\
\hline Enforce & $5.2 \pm 0.1^{A, b}$ & $5.6 \pm 0.1^{\mathrm{A}, \mathrm{a}, \mathrm{b}}$ & $5.8 \pm 0.1^{\mathrm{A}, \mathrm{a}}$ & $5.8 \pm 0.1^{\mathrm{A}, \mathrm{a}}$ & $6.1 \pm 0.1^{\mathrm{A}, \mathrm{a}}$ & $6.0 \pm 0.1^{\mathrm{A}, \mathrm{a}}$ \\
\hline Rely X & $4.5 \pm 0.6^{\mathrm{B}, \mathrm{b}}$ & $5.3 \pm 0.2^{\mathrm{A}, \mathrm{B}, \mathrm{a}}$ & $5.1 \pm 0.1^{\mathrm{B}, \mathrm{a}}$ & $5.1 \pm 0.1^{\mathrm{B}, \mathrm{a}}$ & $5.3 \pm 0.4^{\mathrm{B}, \mathrm{a}}$ & $5.3 \pm 0.5^{\mathrm{B}, \mathrm{a}}$ \\
\hline Variolink & $5.2 \pm 0.1^{A, b}$ & $5.1 \pm 0.1^{\mathrm{B}, \mathrm{b}}$ & $6.0 \pm 0.1^{\mathrm{A}, \mathrm{a}}$ & $5.8 \pm 0.1^{\mathrm{A}, \mathrm{a}}$ & $6.2 \pm 0.1^{\mathrm{A}, \mathrm{a}}$ & $6.2 \pm 0.1^{\mathrm{A}, \mathrm{a}}$ \\
\hline
\end{tabular}

In each column, values with identical capital letters are similar (Tukey HSD, p>0.05)

In each row, values with identical lower case letters are similar (Tukey HSD, $p>0.05$ )

analyzed by multifactor analysis of variance MANOVA (resin-based cement $v s$. activation mode vs. media immersion) and Tukey's HSD test for multiple comparisons. The sorption and solubility data were also submitted to a simple regression analysis. The analyses were performed at a significance level of $\alpha=0.05$.

\section{RESULTS}

For sorption, the MANOVA revealed statistically significant differences for the resin-based cement, activation mode and media immersion independent factors $(p<0.05)$. All the interactions were also significant $(p<0.05)$. The media comparisons by the Tukey's HSD test are presented in Table 1. For all resin-based cements the sorption values were higher after immersion in lactic acid. Irrespective of the immersion media, $\mathrm{E}$ and $\mathrm{V}$ presented higher sorption than $\mathrm{R}$ and $\mathrm{A}$. The lowest sorption was presented by $\mathrm{R}$ dual activated and after immersion in distilled water $\left(17.5 \mu \mathrm{g} / \mathrm{mm}^{3}\right)$. The highest sorption was presented by $\mathrm{V}$ chemically activated and after immersion in lactic acid. Figures 2 and 3 present the curves of increase in sorption vs. immersion time for dual and chemical-activation mode, respectively: (a) A; (b) E; (c) R and (d) V. It can be noted that in general, the highest increase in sorption were reached close to 20 days.

With regard to solubility, the MANOVA detected statistical significance for the resin-based cement $(p<0.05)$ and media immersion $(p<0.05)$ independent factors. Whereas, the activation mode was not significant $(p=0.3155)$. All the interactions were significant $(p<0.01)$. Table 2 shows the result of the Tukey's HSD test. In all immersion media, R presented the lowest solubility values $(p<0.05)$. For $\mathrm{E}$ and $\mathrm{V}$ and for $\mathrm{R}$ chemically activated, immersion in distilled water produced lower solubility values $(p<0.05)$.

\section{DISCUSSION}

Many published studies have analyzed the mechanical behavior of resin-based cements ${ }^{1,4,14,19,29}$. However, until now, little information has been available about resin-based cement degradation in the substances present in the oral environment ${ }^{18}$. In this field, some published studies have shown that the durability of the bond between resin-based cements and dentin can be affected by water immersion and over the course of time ${ }^{7,13}$. According to Bagheri, et al. ${ }^{1}$ (2010) material degradation in the oral environment has two components; one is due to mechanical and the other to chemical degradation. Taking clinical practice into consideration, however, two aspects are noteworthy. Firstly, after restoration luting the film of a resin-based cement will be exposed to the oral environment. Secondly, this film is immediately submitted to severe conditions such as $\mathrm{pH}$ cycling, temperature changes and exposure to oral fluids, e.g., saliva, enzymes and organic 
acids produced by oral biofilm. Based on this, it seems reasonable to imagine that the chemical component would be the first to act on resin-based cement degradation, influencing the mechanical degradation at a later time. Thus, investigations about the chemical degradation could be important to predict resin-based cement behavior in terms of the clinical serviceability of indirect ceramic restorations. Although oral biofilm produces other acids, lactic acid was chosen because Distler and Kröncke $^{6}$ (1983) showed that lactic acid accounts for about $70 \%$ of the total acids present in the human dental plaque. Moreover, these authors found a steeper increase in lactic acid after sucrose rinsing, claiming that this was due to rapid sucrose degradation by lactate-producing bacteria, e.g., S. mutans. Based on this, it is reasonable to speculate that during carbohydrate ingestion, there would be a larger amount of lactic acid in the oral cavity than the other organic acids produced by human dental plaque, i.e., propionic and acetic acids. According to a previous study, 4 is the lowest $\mathrm{pH}$ within the oral biofilm ${ }^{9}$. Based on this and in attempt to mimic the conditions present in the oral environment as closely as possible, the $\mathrm{pH}$ of lactic acid was adjusted to this value in the present study.

In order to withstand the mechanical stresses generated during the masticatory process in vivo, the minimum thickness of the occlusal surfaces of posterior all-ceramic onlays and crowns have to be around 1.5 to $2.0 \mathrm{~mm}^{17}$. Thus, in the present study the specimens polymerized by dual mode were activated through a $2 \mathrm{~mm}$ thick disk of IPS Empress ceramic system in an endeavor to mimic a clinical situation as closely as possible, and to analyze the influence of this response on the degradation phenomenon.

The analysis provided in Table 1 shows that immersion in lactic acid produced the highest sorption values for all the resin-based cements analyzed. This result is in agreement with a previous study ${ }^{18}$. On the other hand, the solubility in this acid was not significantly higher than it was after immersion in artificial saliva and distilled water (Table 2). However, considering the activation mode, it could be noted that for all resin-based cements the solubility values in lactic acid were always numerically higher than those after immersion in the other media. Thus, it seems reasonable to accept the first research hypothesis of the present study. The first part of the above explanation can be interpreted as resin-based cements tending to be more prone to absorbing LA than AS and DW. The findings of Silva, et al. ${ }^{26}$ (2011) could be used to explain this thought. When analyzing the sorption of some resin-based composites, these authors showed a higher rate of sorption after immersion in lactic acid and claimed that this was due to the high level of hydrogen bonds promoted by the $-\mathrm{OH}$ and $-\mathrm{COOH}$ functional groups present in the lactic acid molecule with polar sites of dimethacrylate monomers, i.e., -OH- in Bis-GMA, -O- in TEGDMA and Bis-EMA and - $\mathrm{NH}$ - in UDMA, present in the organic matrixes of the analyzed materials. Since all resin-based cements analyzed in the present study had dimethacrylate monomers in their compositions, the same phenomenon may have taken place here.

In resin-based materials the solubility phenomenon reflects the release of residual monomers and oligomers as well as filler particles and ions from their surfaces ${ }^{8}$. This results in material degradation. From the data shown in Table 2 , it can be deduced that the statistical significance of the independent factor media immersion was influenced by the lowest solubility values of $R, V$ and $\mathrm{E}$ after immersion in distilled water. However, even without significance, it is noteworthy that all the solubility values after immersion in lactic acid were numerically higher than those presented after immersion in the other media. Thus, it is possible that irrespective of the resin-based cement compositions, a common mechanism of action took place after immersion in this acid. Based on this, we speculate whether the solubility of a resinbased cement could increase after a long time of exposition to lactic acid. These explanations corroborate the findings of Silva, et al. ${ }^{25}$ (2012) who showed that some adhesive systems presented significantly lower microtensile bond strengths after immersion in propionic and lactic acid when compared with artificial saliva and claimed that this was due to a common degradative effect produced by these acids.

This aspect could have been influenced by the $\mathrm{pH}$ of the lactic acid used in the present study $(\mathrm{pH}=4)$. It has been well established in the literature that ester groups, such as those present in dimethacrylate monomers, e.g., BisGMA, UDMA, Bis-EMA and TEGDMA, can undergo degradation through hydrolysis in environments with low $\mathrm{pH}$. This hydrolysis process may produce alcohols and carboxylic molecules that may accelerate degradation due to lowering the $\mathrm{pH}$ within the dimethacrylate matrixes ${ }^{11}$. Furthermore, this low $\mathrm{pH}$ may increase the plasticizing effect of lactic acid and cause a reduction in the dimethacrylate matrix interchain interactions, thereby accelerating the rate of water sorption within the material. Reinforcing the role of a low $\mathrm{pH}$ in the degradation phenomenon, Borges, et al. $^{3}$ (2011) recently showed a higher degradation of some resin-based composites after $\mathrm{pH}$-cycling and claimed that this was due to the low $\mathrm{pH}$ of the acid environment used in their study. Moreover, when analyzing the water sorption behavior of some resin-based 
composites immersed in acidic drinks ( $\mathrm{pH}$ of 7.0, 3.9 and 3.1), Rahim, et al.22 (2012) found that the solubility was higher after immersion in the low $\mathrm{pH}$ drink $(\mathrm{pH}=3.1)$. According to these authors, low $\mathrm{pH}$ seems to have an influence on promoting the release of unreacted monomers and inorganic fillers and may additionally cause erosion at the filler surface.

Analyses of Tables 1 and 2 shows that with exception of the solubility values of $\mathrm{R}$ in distilled water, all the sorption and solubility values for the dual-activated mode group were lower than or equal to those presented by the chemically activated specimens. Although these findings do not fully support the second research hypothesis of the present study, from the clinical point of view, these results are important and mean that the physical component of activation, i.e., light-activation, is able to contribute with the conversion of a resinbased cement when activated through ceramic materials $2 \mathrm{~mm}$ thick, with translucence equal to or greater than that of the IPS Empress system.

Figures 2 and 3 show that irrespective of the media immersion and activation mode, all resinbased cements presented an increase in sorption from the first day to the sixth month (180 days), with the highest increase occurring within the first twenty days. These findings support others found in the literature ${ }^{21}$. Even considering that the present study was conducted in vitro, from the clinical viewpoint these results seem to be relevant because they suggest that the resin-based cement film located close to the free gingival margins or within the gingival sulcus, e.g, ceramic total crowns, may undergo fast degradation if exposed to organic acids present in the oral biofilm (lactic acid in the present study).

In the present study, the solubility values ranged from 4.5 to $6.2 \mu \mathrm{g} / \mathrm{mm}^{3}$. These values are in total agreement with the maximum solubility established by the ISO $4049\left(7.5 \mu \mathrm{g} / \mathrm{mm}^{3}\right)^{12}$. On the contrary, four values of sorption ( $E$ : Chemical 46.2/Dual 41.4; and V: Chemical 49.2/Dual 43.1) exceeded the maximum sorption established by the same standard $\left(40 \mu \mathrm{g} / \mathrm{mm}^{3}\right)^{12}$. Interestingly, all these values were reached after immersion in lactic acid. This finding reinforces the above explanation that the degradation of resin-based cements could be more intense in areas where there is higher production of organic acids by the oral biofilm.

Under experimental conditions, $\mathrm{R}$ presented the lowest sorption and solubility values (Table 1 and 2). This behavior could be explained by the fact that $R$ presented a higher degree of conversion than the other resin-based cements analyzed ${ }^{15,20,27}$. It has been well established that resin-based materials with a high degree of conversion and crosslink density may present limited pathways to water diffusion into the polymeric matrix network ${ }^{8}$. The strong negative correlation between the sorption phenomenon and degree of conversion presented by other studies may reinforce this statement ${ }^{10,24}$.

\section{CONCLUSIONS}

In summary, the results of the present study suggest that the exposure to the organic acids produced by the oral biofilm, i.e., lactic acid, may increase the degradation of resin-based cements. Moreover, the physical component of activation, i.e., light-activation, may contribute to a low degradation of the resin-based cements.

\section{REFERENCES}

1- Bagheri R, Mese A, Burrow MF, Tyas MJ. Comparison of the effect of storage media on shear punch strength of resin luting cements. J Dent. 2010;38:820-7.

2- Blatz MB. Long-term clinical success of all-ceramic posterior restorations. Quintessence Int. 2002;33:415-26.

3- Borges MA, Matos IC, Mendes LC, Gomes AS, Miranda MS. Degradation of polymeric restorative materials subjected to a high caries challenge. Dent Mater. 2011;27:244-52.

4- Braga RR, Cesar PF, Gonzaga CC. Mechanical properties of resin cements with different activation modes. J Oral Rehabil. 2002;29:257-62.

5- Della Bona A, Kelly JR. The clinical success of all-ceramic restorations. J Am Dent Assoc. 2008;139(Suppl):8S-13S.

6 - Distler W, Kroncke A. The acid pattern in human dental plaque. J Dent Res. 1983;62:87-91.

7- Duarte RM, Goes MF, Montes MA. Effect of time on tensile bond strength of resin cement bonded to dentine and low-viscosity composite. J Dent. 2006;34:52-61.

8- Ferracane JL. Hygroscopic and hydrolytic effects in dental polymer networks. Dent Mater. 2006;22:211-22.

9- Geddes DA. Acids produced by human dental plaque metabolism in situ. Caries Res. 1975;9:98-109.

10- Goncalves L, Filho JD, Guimaraes JG, Poskus LT, Silva EM. Solubility, salivary sorption and degree of conversion of dimethacrylate-based polymeric matrixes. J Biomed Mater Res Part B Appl Biomater. 2008;85:320-5.

11- Gopferich A. Mechanisms of polymer degradation and erosion. Biomaterials. 1996;17:103-14.

12- International Organization for Standardization. ISO 4049:2009(E): Dentistry - polymer-based filling, restorative and luting materials. Geneva: ISO; 2009.

13- Kitasako Y, Burrow MF, Katahira N, Nikaido T, Tagami J. Shear bond strengths of three resin cements to dentine over 3 years in vitro. J Dent. 2001;29:139-44.

14- Knobloch LA, Kerby RE, Seghi R, Berlin JS, Lee JS. Fracture toughness of resin-based luting cements. J Prosthet Dent. 2000;83:204-9.

15- Kumbuloglu O, Lassila LV, User A, Vallittu PK. A study of the physical and chemical properties of four resin composite luting cements. Int J Prosthodont. 2004;17:357-63.

16- Liu Q, Meng X, Yoshida K, Luo X. Bond degradation behavior of self-adhesive cement and conventional resin cements bonded to silanized ceramic. J Prosthet Dent. 2011;105:177-84.

17- Marchack BW, Futatsuki Y, Marchack CB, White SN. Customization of milled zirconia copings for all-ceramic crowns: a clinical report. J Prosthet Dent. 2008;99:169-73.

18- Marghalani HY. Sorption and solubility characteristics of selfadhesive resin cements. Dent Mater. 2012;28:e187-98. 
19- Nakamura T, Wakabayashi K, Kinuta S, Nishida H, Miyamae M, Yatani $\mathrm{H}$. Mechanical properties of new self-adhesive resin-based cement. J Prosthodont Res. 2010;54:59-64.

20- Noronha Filho JD, Brandao NL, Poskus LT, Guimaraes JG, Silva EM. A critical analysis of the degree of conversion of resin-based luting cements. J Appl Oral Sci. 2010;18:442-6.

21- Ortengren $U$, Andersson F, Elgh U, Terselius B, Karlsson S. Influence of $\mathrm{pH}$ and storage time on the sorption and solubility behaviour of three composite resin materials. J Dent. 2001;29:3541.

22- Rahim TN, Mohamad D, Md Akil H, Ab Rahman I. Water sorption characteristics of restorative dental composites immersed in acidic drinks. Dent Mater. 2012;28:e63-70.

23- Sideridou I, Tserki V, Papanastasiou G. Study of water sorption, solubility and modulus of elasticity of light-cured dimethacrylatebased dental resins. Biomaterials. 2003;24:655-65.

24- Silva EM, Almeida GS, Poskus LT, Guimarães JG. Relationship between the degree of conversion, solubility and salivary sorption of a hybrid and a nanofilled resin composite. J Appl Oral Sci. 2008;16:161-6.
25- Silva EM, Almeida GS, Poskus LT, Guimarães JG. Influence of organic acids present in the oral biofilm on the microtensile bond strength of adhesive systems to human dentin. J Biomed Mater Res Part B Appl Biomater. 2012;100:735-41.

26- Silva EM, Goncalves L, Guimaraes JG, Poskus LT, Fellows $\mathrm{CE}$. The diffusion kinetics of a nanofilled and a midifilled resin composite immersed in distilled water, artificial saliva, and lactic acid. Clin Oral Investig. 2011;15:393-401.

27- Souza-Junior EJ, Prieto LT, Soares GP, Dias CT, Aguiar FH, Paulillo LA. The effect of curing light and chemical catalyst on the degree of conversion of two dual cured resin luting cements. Lasers Med Sci. 2012;27:145-51.

28- Spinell T, Schedle A, Watts DC. Polymerization shrinkage kinetics of dimethacrylate resin-cements. Dent Mater. 2009;25:1058-66. 29- Walker MP, Spencer P, David Eick J. Mechanical property characterization of resin cement after aqueous aging with and without cyclic loading. Dent Mater. 2003;19:645-52.

30- Wei YJ, Silikas N, Zhang ZT, Watts DC. Diffusion and concurrent solubility of self-adhering and new resin-matrix composites during water sorption/desorption cycles. Dent Mater. 2011;27:197-205. 